Original Contribution

\title{
STORY AS A LEARNING TEXT IN FOREING LANGUAGE EDUCATION IN PRIMARY SCHOOL
}

\author{
B. Lekova-Dimitrova* \\ Faculty of Education, Trakia University, Stara Zagora, Bulgaria
}

\begin{abstract}
The present article is focused on the specific character of the story as a learning text in foreign language education in primary school. For this purpose a set of linguistic, psychological and cultural criteria for selecting the story-telling material is taken into account. A set of techniques is elaborated for the children's future success as story-tellers. Efficient and attractive ways of learning vocabulary and grammar and teaching pronunciation, reading and writing are presented. An example of lesson plan is given to illustrate how the language - learning skills could be developed.
\end{abstract}

Key words: story, advantage, imagination, language skills, language functions, story-telling material, linguistic criteria, psychological criteria, cultural criteria, story-based lesson

\section{INTRODUCTION}

There is hardly a person in the world who has not heard the formula "Once upon a time" or experienced the pleasure that follows after it. You can find it in every language, in every corner of the world. Story seems to be one of the elements of every culture. It is a universal phenomenon which is essential to the understanding of human communication and thought. It is also both product and source of discoveries about people, their environment, as well as about their mental and spiritual development. Through telling stories to one another, people not only extend knowledge of themselves, they acquire a sense of the language they are communicating in, of its structures, in order to arrange their thoughts and create meaning.

It is obvious that children enjoy listening to stories in their mother tongue and understand the conventions of narrative. The fact that they become filled with anticipation when they hear the formula "Once upon a time" speaks for itself. In this case storybooks are ideal for the purposes of providing an introduction to the foreign language presented in a context that is familiar to the child. There are several advantages of

*Correspondence to: Branimira Lekova-Dimitrova Faculty of Education, Trakia University, Stara Zagora, Bulgaria,br.lekova@abv.bg spending more time on story-telling in class. For children for whom English is a second language, story-telling sessions are an effective means for the use of language in a meaningful context.

Story-telling is an ideal exercise for the imagination. Children can become personally engaged in a story as they identify with the characters and try to interpret the narrative and illustrations. On the other hand stories are a useful instrument in linking imagination with the child's real world. They help children make sense of their everyday experience and strengthen bonds between home and school. Participation in story-telling sessions contributes to the development of thinking skills which include: reflection on the content of the story in order to master it; capacity of integrating his/her own emotional responses in order to convey these to the listeners; ability to analyze what aspects of the story to highlight; mental outline of the sequence of events for easy recall; elaboration of a method of presentation suitable to the story and the intended audience (1).

Story-telling also develops language skills, which include: combining words and phrases into meaningful units; organizing these meaningful units into the larger context of a story; enriching vocabulary.

Story telling provides active participation in literature and language sessions. Children should 
be engaged in meaningful activities and situations where established goals are pursued. Thus literature stimulates language learning.

If the four components of language (listening, speaking, reading and some writing) are integrated in the activity of story-telling, students can become more aware of their power as narrators and writers. Story-telling is a stimulating way to overcome inhibitions caused by more traditional activities such as book reviews or set of comprehension questions. The less successful language-users are restrained because their critical skills are not well developed, and those students who have a higher language proficiency become bored with the predictability of the activities. Story-tellers are much more willing to demonstrate their responses to the narrative in discussions preceding the retelling. They feel much freer to contribute because there is no threat of critical appraisal from the teacher (2).

When the class gathers to share the stories, a friendly intercourse takes place and a kind of fellowship is created. Class members accept ideas and knowledge by exchanging and sharing stories, and the former are reinforced over time. A spirit of respect to individual tastes will come to prevail in the group.

After considering the advantages of bringing story - telling activities into the classroom, it is also necessary to bear in mind some specific features of children's acquisition of literary work which are important for the selection of story material to be used. Children respond to stories much more passionately than adults. This strong emotional response is closely linked with thinking and memory. Cognitive processes go hand and hand with the emotional reaction to the contents and assessment of it depends on both. That is, when children come across images and pictures created by means of the language, they not only get information on who the characters are and what is happening but establish relationships between the characters and notice the way of description.

According to P. Russev, there are four stages of acquisition:

1. A stage of sensual and emotional perception of the information which generates the formation of emotions and attitudes.

2. A general penetration into the imagery and thoughts over the between images and reality.
At this stage associations with the reader's experience appear.

3. Enrichment of the students' experience with new issues, discovering new layers in the contents.

4. Examining gender, genre and composition features and peculiarities; notice of the ingenuity of the author's talent (3).

Story-telling sessions are an aid to the teacher. They can include various comprehension activities which enable the teacher to predict possible errors the children can make in a specific context, consider different ways of predicting errors, practice correction techniques.

Teachers can use storybooks as an alternative to the course book. S/he can exploit storybooks as a short basic syllabuses in their own right. There are three main aspects in which stories can add to learning in the whole school curriculum:

1. Stories bring the notion of ideas (e.g., colour, size, shape, time, cause and effect, etc.)

2. Stories are a useful tool in exploiting the ways of learning. This includes:

- developing thinking procedures (e.g., comparing, classifying, concluding, predicting, problem-solving, hypothesizing, planning, etc.);

- elaborating strategies for learning English (e.g., word-guessing, memory-training, self-testing, etc.);

- organizing work (e.g., making and interpreting charts and graphs, making and learning to use dictionaries, etc.).

3. Story can also be used to add to other subjects in the curriculum, such as: Mathematics ( numbers and quantity, measuring), Biology (animals, plants), History (chronology/ the passing of time), Geography (using the map and an atlas, the weather and climates), Music and Drama (singing songs, playing instruments, role-play, miming) (4).

As has already been pointed out, both children and teachers benefit from bringing story into the classroom. It is true that to use story-telling strategies requires a much more scrutinized preparation for the lessons, and, respectively, much more time and efforts. The teacher is compelled to make use of the story-telling material either in its own right - and that would mean elaborating a syllabus and appropriate organization of activities and planning a time or as a supplement to the already existing syllabus which would need adapting and adjusting it to the course book topics. 
THE STORY-TELLING MATERIAL AND METHODS

The selection of story-telling material should be based on a set of criteria in the linguistic, psychological and cultural aspects, although there are no firm rules for book selection. The level of the pupils is an important factor in selecting the linguistic material. The teacher should carefully consider the appropriateness of the language level and avoid too easy or too difficult texts. The story has to contain vocabulary, structures and language functions included in beginner syllabuses. If the story contains rhythms or various patterns, the pupils might enjoy imitating and repeating these. Psychological criteria relate to the use of pictorial devices, fostering participation and age characteristics.

1. Use of pictorial devices. The colourful illustrations and other visuals should relate to the text and support the children's understanding. They should be big enough for the whole class to see or distributed among all of them.

2. Fostering participation. To encourage participation the teacher will have to select texts involving repetition on the part of the children, thus providing pattern and pronunciation practice. In this way memory skills are developed. Repetition also allows the pupils to predict what is coming next in the story and to build up their confidence. The story may contain elements which involve children into a discussion on their own experiences. It can also develop their imagination.

3. Age characteristics. Children's interests and tastes in storybooks changes as they get older, and the language teacher needs to determine what book will appeal to different age groups.

Six-to eight years old are developing more confidence as they acquire new skills and seek greater independence. They also have a sense of justice and are shifting from their children's egotism to being more responsive to others. They show a keen interest in the world around them. This is the age when the sense of humour is developing. They are also more able to distinguish fantasy from reality, but, on the other hand, enjoy pretending and imagining. The Magic Porridge Pot is a good tale for this age of group.

Nine-to twelve-year-olds are already starting to appreciate other points of view. Children at this age enjoy stories that extend their horizons. The books which would be relevant are adventures,
LEKOVA-DIMITROVA B.

fantasy or reality, and an important feature of these is that they contain a well-developed plot and credible characters. From the fairy-tales one could choose such stories as Puss in Boots and The Beauty and the Beast.

The success of story - telling selection depends also on the cultural criteria.

The selected stories should contribute to children's growing interest in the target language culture and create positive attitudes towards these. Here it is important to note that this can be achieved only if the language included in the stories is representative of the target culture. Nevertheless, it should not be too culture specific, because it may be difficult for the children to understand.

In two words, choosing books for the L2 classroom requires careful consideration of the language as well as the supporting illustrations and the potential of interest. As for the language, it needs to be understandable, enjoyable and memorable. If these conditions are met, pupils will be able to remember even more complicated words or phrases, and their knowledge of the L2 will be extended.

For elaboration of a method of presentation suitable to the story and the intended audience we will have to do a brief review of the main methods in teaching English as a foreign language.

It is an established practice in considering the various methods of teaching L2 to start with the traditional grammar-translation method which is still used in many school systems. The main focus in a traditional primary syllabus is grammar. The succession of grammatical structures is often determined by traditional views on L2 presentation. The organization of the material is based on simplicity, regularity, frequency and contrastive difficulty. It has been long criticized, however, mostly for the lack of the communicative aspect in foreign language learning.

The reading method appeared as a reaction against the direct method which emphasized aural-oral skills and almost prohibited reading and writing. The former advocated focus on reading as a more attainable and appropriate goal for schools. In the USA and Canada until the World War II intensive and extensive reading was accompanied by the teaching of grammar rules based mainly on the structures found in the 
reading extracts. Hence, although the reading method was much more flexible than the grammar translation, a syllabus based on the former would be again of the previously described type with minor variations as regards its essence.

The over-reaction to the direct and reading methods crystallized in the audio-lingual method which flourished in the United States between 1950 and 1960. It stemmed from the structural approach to foreign language teaching, which, in its turn, was influenced by the ideas of structural linguistics. The audio-lingual method postponed reading and banned the study of grammar replacing it by pattern practice drills which were the main activities of the lesson. The material was presented in long dialogues centered on one or more carefully graded structures. A similar development in Europe was reflected in the audio-visual method which also gave precedence to spoken language, this time using aids such as tape recorders, film strips and other pictorial devices. Both methods had the disadvantage of emphasizing the mechanical repetition of structures too much. The goal was mainly to master the sentence patterns rather than develop real communicative use of language.

In situational syllabus, the center of interest was the various social situations presented again in dialogues. Emphasis was placed on the setting and social roles of the participants which predetermined the type of conversations. As L. Pantaleoni writes: "Sequencing criteria (for the syllabus designing) are based on a prediction of what situations the learners will have to deal or cope with. Materials tend to be based on phrasebook language easily memorable but rather soulless, aseptic, uncreative." (5).

The notional functional approach to language teaching has the advantage of being studentoriented and responsive to individual needs. The major concerns of a notional-functional syllabus are the semantic content of language and the actual use of what is being learned. The sequencing is established again, as with the previous method, on the basis of prediction of which language functions will be relevant to the L2 users' needs. And, again, it is more productoriented and not so relevant for the purposes of teaching English to children in primary school.

A notional syllabus, according to L. Pantaleoni, is what a teacher of foreign language needs in order to "shift the focus from usage and rehearsal to real life use" (5). It should contain process-oriented, procedural or task-based sets of activities. These will enhance cooperation in learning, develop thinking and take advantage of other disciplines. An interdisciplinary work can make the foreign language learning appealing to the children. In a notional-based syllabus the foreign language services primary school activities done to 'discover the world' through the acquisition of notions (such as size, quantity, time, space, cause and effect) which explain and describe spatial, temporal and causal relations.

In defense of the notional syllabus, one can point out its major advantage, that is, its orientation towards process. This means that both children's and teacher's attention will not be focused on the number of units in the student's book but on the activities carried out in the classroom. The notional syllabus should contain listings of language functions related to games, interaction among peers and with adults, television, cinema, drama, etc.

\section{DISCUSSION}

The success in story-telling depends mainly on the presentation. A successful story is the one that can win the attention of the audience. To know how achieve this, it is necessary to examine and choose between different techniques. Those which have proven to contribute to the overall impact on the listeners, should be employed in the presentation of a story.

\section{Preliminary work}

It is useless to point out that a well-prepared presentation makes half the success of the story. The following steps are to be considered in the preparation process:

1. Choice of a story. The starting point is the choice of a story. The material should be selected according to the listeners' interests. This, as it was already noted, depends on a set of linguistic, psychological and cultural criteria. The text should not present any substantial difficulties to the children. At the same time, it should not be oversimplified, for the pupils need to come across some new items the meaning of which would be easy to guess. However, if there are unfamiliar words in the text, it would be advisable to list them and find a way to explain them before the presentation. For example, the children are not likely to know the word 'ogre', while the Ogre in "Puss in Boots" plays an important part in the episode of outwitting. In this case, it is better to explain the word directly- 
'a giant eating people''- because it pertains only to the world of folk-tales. But if the unknown word is one of frequent use in our everyday life, such as 'merchant' from the story The Beauty and the Beast, the teacher should try to create associations which lead to the notion of a tradesman through related lexical items like: 'buy', 'sell', 'shop', etc. This practice will enhance the knowledge of concepts from the real world.

2. Visual aids. They can be some story cards, puppets, slides, miscellany of objects like clothes, boots, belts, lamps, ropes, etc., would make the narrative more vivid, especially in the case of dramatizations and some aural aids like CD and DVD.

\section{Introductory activities}

The preparation for a story-telling session involves introducing the content, concepts and lexical items of the story:

1. Content. The teacher can create the environment for the target story by: involving the students' experience relevant to the content of the story (travelling, shopping, eating, etc.; selecting other stories with a similar ideas beforehand to help the children recall them before hearing the target story; presenting a brief resume of the story .however, the teacher should be careful in doing this because it can destroy the magic of the story for the children).

2. Concepts. This again includes associations from previous experiences of books or other school subjects, for instance, routes, time, geographical notions, such as mountains, valleys, hills, etc.

3. Lexical items. Before telling or reading the story it is necessary to revise some lexical items and key structures already taught or introduce the new words and phrases in a suitable way. This can be done by holding pictures and asking questions to elicit the appropriate answers, sometimes even by stimulating the students.

\section{Story-telling techniques}

The story-telling techniques that need to be taken into consideration for the success of the presentation are the story features and the performance. They are devoted both to teacher and students.

1. The story features. The teacher/student uses the techniques to memorize the story-line (storymapping, making story cards, etc.). A good beginning and a good end are essential for a successful performance. Therefore, the first and the concluding sentences should be remembered (e.g. with the help of visual imagery). This will
LEKOVA-DIMITROVA B.

attract and hold the attention of the listeners throughout the whole story. The teacher/student should check if there is a need to learn by heart certain words and phrases which are essential for the flavor of the story. If not, it is preferable to use one's own words. It is not necessary to employ for this purpose all the lexical items contained in the narrative, but select the key words.

2. The performance. Intonation and gestures are important aspects of the performance. To attract the listeners' attention it is necessary to involve various facial expressions and intonation corresponding to the 'filling' of the narrative: the characters' feelings and behavior, ideas and events. It is also advisable that if the story-teller prefers standing while telling the yarn, s/he establishes a contact with the class, e.g. eyecommunication, gestures with arms or even legs, moving about or learning towards the audience. In doing this, however, one should always make sure that the audience sees his/her face and hears the story-teller's voice. A very successful tool for creating a general atmosphere of anticipation is the use of pauses in 'strategic' positions. This however, again requires carefulness on the part of the performer in order not to overplay it.

\section{LANGUAGE LEARNING SKILLS AND STORY-TELLING}

Story-telling sessions can be used to develop not exclusively communicative skills (listening and speaking) in children but other language skills as well. In order to make the best of these lessons, the teacher has to be aware of the most efficient ways of presenting vocabulary and grammar and teaching pronunciation, reading and writing. There is always a risk in introducing vocabulary and grammar in the story-telling session because, if it is done in the traditional way, the children become less enthusiastic about these lessons. That is way the activities in which the children are involved to learn new words, phrases and grammatical structures must be carefully prepared and elaborated.

We will examine in brief how language-learning skills could be developed.

\section{Vocabulary}

Stories usually contain a lot of lexical items that children need not to learn but only recognize at a certain stage of their L2 knowledge. That is way the teacher should select items which are relevant to the level of the pupils and try to organize them in a meaningful way. Vocabulary must be introduced in a clear and vivid context 
and here the illustrations may aid the understanding and remembering process.

New words can be presented in: groups of lexical items (sets), e.g. clothes, furniture, vehicles etc.; colour groups, e.g. different objects of the same colour; rhyming sets (words that group in rhymes, e.g. back-track, wall-doll, etc.); grammatical sets (prepositions - in activities stimulating a search for something; adjectives in groups of synonyms or antonyms; verbs related to similar or contrasting activities, etc. It is necessary to involve the active participation of children in learning the new lexical items through using their senses (touch, smell, sense, hearing and sight). New vocabulary can be introduced with the help of the visual aids to facilitate memorization and create mental associations in children.

After learning a new word, the children need to be given the opportunity to practice it. This can be done in a number of ways depending on the given lexical item. For example, if it is a concrete noun (most nouns taught at primary school are concrete), then the real object denoted by it can be grouped with other real objects on a table. The teacher points at or removes the given object and asks the pupils what is missing. In a similar way, if prepositions are to be practiced, the class may hide an object in the absence of a student who then comes back and asks questions like: 'Is it on the wall/ under the table/ in the cupboard etc.?'

Miming can also be helpful in guessing activities, jobs or animals.

Labeling pictures and parts of pictures and objects is another way for recalling lexical items. Matching pictures to words is also a simple tool for memorizing words.

There also a lot of games that assists remembering the words. One of them is whispering the new words in a row and listening to the final version of the last student to check whether it has been correctly understood and memorized. Another is accumulation of words when a student says, e.g. "I want an apple", and the next one continues: "I want an apple and a peach" and so on. Crosswords and hangman are very helpful at revising spelling. And, of course, there are a lot more ways of memorizing and checking vocabulary which the teacher can employ during the lesson.
Individual and group work should also be encouraged. The students can organize vocabulary that is introduced in different ways: by topic; in alphabetical order; by use of vocabulary cards (with pictures on one side and words on the other), etc. This will help to integrate the knowledge acquired so far.

\section{Grammar}

One of the advantages of the story-telling sessions is that children are usually fond of listening to one and the same story over and over again. This is a very important factor because stories introduce grammatical structures in a natural way and sometimes the teacher does not have to present them explicitly and risk at confusing the primary students. Repetition of structures is done willingly by the children who are able to memorize them during the reading or telling rather than in separate practice drills.

\section{Listening}

The listening comprehension activities are extremely important for developing the communicative aspects of language learning. However, this does not mean the ability simply to listen and to memorize lexical items or grammatical moments in the story. Understanding of the text is more important than remembering the original words contained in it. Developing the listening skills in children requires careful approach on the part of the teacher. This is because when the students are exposed to oral text, they are usually afraid of possible failing to understand what it is all about. That is why it is necessary that developing the listening skill is bound with strategies of building up confidence with children.

1. Supporting activities. First of all, the children need to know that they are not expected to remember every word from the text. The teacher must make it clear that they need to focus only on specific points or follow the main sequence of events without going into details. Another option is to choose a smaller part of the story and present it in order to make it easy for the students to follow.

There are several possibilities to deal with unfamiliar words in the context. One is to support understanding with visual aids (pictures, slides, objects) or gestures, facial expressions, stress, intonation, etc. Another is to allow the children to foresee what is to follow. That is possible because almost all stories have recurrent patterns. The awareness of one's ability to predict generates confidence. 
LEKOVA-DIMITROVA B.

2. Listening tasks. The students need to know the purpose of listening and what they are going to do before, during and after the listening comprehensive activity. This means they have to know their tasks. The latter may vary in range:

- The "Listen and Repeat" tasks are included in every textbook and helpful in improving pronunciation and memory;

- $\quad$ Listening and miming;

- $\quad$ Pictures drawn while or after listening. This activity is successful when the text contains concepts like size, shape, colour, etc. Another way to employ this activity is to have incomplete pictures with missing items that have to be added by children during or after listening. There can be also a range of pictures available which have to be matched to what is heard and arranged in the right order.

\section{Speaking}

Speaking is an important part of the communicative aspect, since it is the most apparent everyday output of language learning. Children are usually much more interested in learning to speak rather than learning to write. That is why in the early stage of learning English the emphasis is put on speaking. This involves activities for developing proper pronunciation through introducing of words of English origin, such as 'radio', 'zebra', 'sandwich', etc. Thus, the pupils encounter for the first time the features of English pronunciation. Speaking activities at the beginners; level usually include some social English: greetings, expressing gratitude, wishes, regrets, asking permission, some classroom routines, etc. These patterns are easily memorized and lay the basis for developing communicative skills.

To develop both accurate pronunciation and fluency in children, it is necessary to elaborate two groups of respective activities.

Fluency can be developed through a range of activities, such as: retellings of stories in which the students say the lines of the characters; roleplay which gives the opportunity to practise the language contained in a story in another context; the so called 'jigsaw activities' that allow children to ask questions in order to fill in an information gap, etc.

Pronunciation can be developed through: songs and rhymes which help children to become aware of the way certain English words sound alone in connected speech, of stress and rhythm (these can be accompanied by clapping to reinforce the rhythmical patterns); practicing words included in the stories by emphasizing certain English sounds (if there are peculiar consonants like the characteristic English [ð], the teacher should also show how it is formed with the lips, tongue and teeth; the same will hold true for the English vowels); introducing lexical items before story-telling, focusing on individual sounds and then including them in a meaningful context presenting also intonation patterns etc.

\section{Reading and writing}

The primary teacher should not spend much time on reading and writing activities. It is true that hearing the spoken word should be connected with seeing its written form. This will lay the grounds for more extensive reading and writing in the secondary school. The tasks that the primary teacher will have to fulfill at an early stage of children's learning L2 should include the following skills:

- Reading and, if possible, writing of already familiar words (the latter can be done in the form of a game, such as "hangman", or labeling pictures and filling in charts);

- Grouping words in word sets according to a given principle (colour, shape or other relations);

At a later stage, a wider range of more complex activities can be introduced:

- $\quad$ Arranging written words in sentences (this can be done in the form of sequencing cards with words written on them or arranging pictures and writing the words below them);

- $\quad$ Arranging sentences in the right order;

- True/false activities: verifying statements helps checking listening or reading comprehension;

- Imitating different kinds of texts in a written form (invitation cards, Christmas cards, letters or even simple stories); gradually, imitation will be replaced by creativity.

- Composing sentences (asking questions, giving answers, describing actions, etc.) and texts.

As can be concluded from the above list, reading and writing activities can be helpful not only in developing language learning skills but also in favouring creativity in children. Another interesting point is that some other mental abilities in the students are developed. Getting involved in the above-listed activities helps children to establish links and relationships between objects and actions and become aware 
of a logical or illogical sequence of events. This will aid not only the L2 acquisition process but also the overall approach of the children towards learning. Although it is a peripheral benefit, it is at the same time a significant one and should be taken into account when designing lesson plans.

\section{LESSON PLANS}

We will present an example of lesson plan based on the fairy-tale "The Magic Porridge Pot", classified by the Ladybird Publishers' as 1 Grade book. The example of this lesson plan illustrates how language-learning skills could be developed.

\section{Grade 1}

"The Magic Porridge Pot"

A. DESCRIPTION, OBJECTIVES AND

\section{MATERIALS}

1. Essence of the story: an entertaining story about a magic porridge pot

which cannot stop cooking because the mother cannot remember the magic words until her daughter comes back home.

2. Linguistic features

A simple text with repetitive imperative sentences, such as: "Cook, little pot, cook!", "Stop, little pot, stop!". There is also a recurrent sentence: "The pot went on and on, cooking more and more porridge". - with minor variations: "And still the little pot went on (and on), cooking more and more porridge!", "It just went on and on, cooking more and more porridge".

\section{Linguistic objectives}

\section{SKILLS:}

- $\quad$ Listening to instructions; remembering the repetitive structures; noticing and remembering the sequence of events, some of which are matched by extent of porridge production.

\section{FUNCTIONS/STRUCTURES}

- $\quad$ Using imperatives for giving orders

- Getting familiar with the structure "so...that" ("They were so poor that one day they found they had nothing left to eat"; "She was so hungry that she began to cry".).

- Getting familiar with the structure "to have nothing left to eat"

VOCABULARY:

- $\quad$ Nouns, which might be unfamiliar, such as: porridge, pot, widow, woods, worries, world; some familiar nouns like: girl, woman, house, kitchen, floor, streets, town, etc.

- Adjectives: poor, hungry, full of; some familiar adjectives like: small, little, old, good
LEKOVA-DIMITROVA B.

- Verbs and verb forms: to cook/cooking, to stop, eat, to go on and on, to be well-fed, to feel (hungry), to be filled with, to reach, to come back, to happen, to cry, to say.

- Adverbs: soon, now, just, still, at once, all over, more and more, nearly, at first, at last, then.

PRONUNCIATION:

a) Intonation:

"Why are you crying, my child?"

"Cook, little pot, cook!"

"And still the little pot went on, cooking more and more porridge!"

b) Stress:

Weak forms for a, and, of, from, for, to, the: [ə], [ən], [əf], [frəm], [fə], [tə], [ðə], [ði:]

c) Individual sounds: [u] as in cook, good; [ว:] as

in more; [o] as in pot, stop; [^] hungry; [ai] my; $[\mathrm{t}]$ ] child; [dz] porridge; [ð] they; $[\theta]$ nothing CONCEPTS:

- $\quad$ Acquiring a sense of beginning and an end of a production process, of emptiness and abundance, of micro and macro environments (from a kitchen to the world).

Materials

A pot, a pack of oat flakes, a big wooden spoon, an apron. If possible, a girl's doll kitchen set and a prefabricated toy town or several houses and trees (plastic or paper ones).

Large illustrations of the main events.

B. LESSON PROCEDURES

1. Have the new words written on the board and point at them, when necessary. Point at the pot (the object) and say: "This is a pot". Point at the pack of oat flakes. As the label is likely to be in L1, it will be easier to explain the meaning of this kind of food. Proceed with asking questions about cooking demonstrating the steps in preparing a meal.

-What do you do when you are hungry? (Press your stomach and, if necessary, translate into L1).

Elicit: Eat. Cook.

-Where do you usually cook?

Elicit: In the kitchen.(Put the apron on and place the pot on an improvised stove).

-What do you put into what?

Elicit: Oat flakes into the pot. (Pour the contents of the pack into the pot).

-What do you do then?

Elicit: Cook. (Stir the contents of the pot).

-What do we do when the porridge is ready?

Elicit: Eat. (Mime eating).

-Where do you eat it?

Elicit: At the table. 
2. Tell the pupils you are going to read a story about a magic porridge pot. Acquaint them with the main characters (the little girl and her mother). Explain the meaning of "widow" ("a wife whose husband has died" in a L1, if necessary). Explain they live in a town and are very poor. Add they have nothing to eat and are very hungry.

3. Reading/Telling the story. The general understanding may be reinforced by actions: gestures, illustrations, demonstration of settings (house, woods, town), pouring the content of the pot all over the doll set and the toy town according to the stage of porridge production. Pause after the recurrent sentences: "Cook, little pot, cook!", "Stop, little pot, stop!", "And the pot went on and on, cooking more and more porridge...".

4. After reading/telling the story, ask the pupils some general questions in order to check understanding. It is better to start with: "Do you like the story?" Then proceed with asking about the features of the characters. To help the pupils remember more details, you can use multiple choice or contrasting questions: Is the girl big? Is she little? Is she happy before meeting the old woman? Do the little girl and her mother eat every day? Do they have enough food? Are they poor or rich?

Proceed with questions about the plot: Where does the girl go to play? Does she meet an old man? Is the woman young? What does the woman give to the little girl? Does the girl come back home? Is her mother happy? Is the little girl happy?

What are the magic words? Can the mother remember them? Can she stop the pot from cooking more and more porridge? Is the house/the street/ the town full of porridge? Can the little girl stop the porridge?

\section{Make Tables 1 and 2}

Table 1. Character study

\begin{tabular}{|l|c|c|c|c|}
\hline \multicolumn{7}{|c|}{ CHARACTER STUDY } \\
\hline MOTHER & \multicolumn{2}{c|}{ LITTLE GIRL } & OLD WOMAN \\
\hline before & after & before & after & old \\
\hline unhappy & happy & little & little & good \\
\hline hungry & not hungry & unhappy & happy & helpful \\
\hline sad & smiling & hungry & not hungry & mild \\
\hline bad-looking & good-looking & sad & smiling & smiling \\
\hline thin & & bad-looking & good-looking & \\
\hline & & thin & & \\
\hline
\end{tabular}

Table 2. Setting study

\begin{tabular}{|c|c|c|c|c|}
\hline \multicolumn{5}{|c|}{ SETTING STUDY } \\
\hline \multicolumn{2}{|c|}{ HOUSE } & \multirow{2}{*}{ FOREST } & \multicolumn{2}{|c|}{ TOWN } \\
\hline before & after & & before & after \\
\hline poor & joyful & green & \multirow{2}{*}{$\begin{array}{c}\text { clean streets } \\
\text { and houses }\end{array}$} & \multirow{2}{*}{$\begin{array}{l}\text { streets full o } \\
\text { porridge }\end{array}$} \\
\hline bleak & $\begin{array}{l}\text { full of } \\
\text { porridge }\end{array}$ & full of trees & & \\
\hline
\end{tabular}

6. Read the story again. Ask a few volunteers to draw events from the story on different parts of the blackboard. Ask all the rest if they remember the event, and then, what happened before and after it.

7. Organize a "hangman" game using some of the words from the story.

\section{CONCLUSIONS}

Both students and teachers benefit from bringing story into the classroom. Story-telling enables learning, contributes to the development of language learning skills and fosters imagination. It is an effective means for using the foreign language in a meaningful context. On the other hand, much of the tediousness common for many classrooms will disappear opening the way to creativity and development. The collective ideas appearing in story-telling sessions can serve for a stepping-stone for future classroom activities.

In order to collect the appropriate material for the story-telling sessions, the teacher will have to examine carefully the possibilities for devising his/her own syllabus or complementing the existing one in a most successful way. For this purpose, s/he will have to take into account the 
set of criteria for selecting the story-telling material.

Story-telling helps the pupils to distinguish the elements of a narrative (setting, characters, plot). The teacher will have to elaborate a set of techniques. This is of crucial importance for the children's future success as story-tellers.

Story-telling sessions can be used to develop not exclusively communicative skills (listening and speaking) in children but the other languagelearning skills as well. In order to make the best of these lessons, the teacher should be aware of the most efficient and, at the same time, attractive ways of presenting vocabulary and grammar and teaching pronunciation, reading and writing in order to prevent boredom in the classroom.

\section{REFERENCES}

1. Livo, N., Rietz, S. Storytelling: Process and Product, Englewood, Colorado: Libraries Unlimited, 1991.

2. Jennings, C. Children as story-tellers. Melbourne, Australia: Oxford University Press, p.4, 1991.

3. Russev, P. Psychology of the Child's Acquisition, V.Tarnovo, p.203, 2004.
LEKOVA-DIMITROVA B.

4. Gail,El., Brewster, J., Tell it Again! The New Storytelling Handbook for Primary Teachers, Amazon, Fr., 2002.

5. Pantaleoni, L. Syllabusing at primary level: the Italian Perspective; 'Teaching English to Children', p.306, 1991.

6. Hamilton, M., \& Weiss, M. Children tell stories. Katonah, NY: Richard C. Owen, 1990.

7. Gardner, H. The Unschooled Mind- How children think and how schools teach, London: Fontana Press, 1993.

8. Belcheva, V., For reading and understanding the tales in early learning German as a foreign language, In: Foreign language learning, book 3, pp. 39-43, 2005.

9. Belcheva, V., Storytelling and their educational impact in the context of early learning German as a foreign language, In: Foreign language learning, book 5, pp. 49-58, 2005.

10.Belcheva, V., Educational potential of the story in the context of early foreign language learning in primary school, Shopov, T., Malinova, L., Valkanova, V. (compilers), University course on early foreign language learning, Sofia, University Edition "St. Kl. Ohridski”, pp.245-257, 2008. 